\title{
Influential Factors Affecting Protective Coping Behaviors of Flood Disaster: A Case Study in Shenzhen, China
}

\author{
Weiwei Cao ${ }^{1}$, Yi Yang ${ }^{2, *}$, Jing Huang ${ }^{1, *}$, Dianchen Sun ${ }^{1}$ and Gaofeng Liu ${ }^{1}$ \\ 1 Institute of Management Science, Business School, Hohai University, Nanjing 211100, China; \\ cww@hhu.edu.cn (W.C.); dcsun@hhu.edu.cn (D.S.); gaofengliu@hhu.edu.cn (G.L.) \\ 2 Teachers College, Columbia University, New York, NY 10012, USA \\ * Correspondence: yi.y@columbia.edu (Y.Y.); j_huang@hhu.edu.cn (J.H.)
}

Received: 21 July 2020; Accepted: 13 August 2020; Published: 16 August 2020

\begin{abstract}
As the risk of urban flooding increases worldwide, floods seriously endanger the safety of people's lives and property. Understanding the protective coping behaviors of the public in flood disasters is crucial to the implementation of effective flood mitigation measures and flood risk management. In this study, influential factors affecting protective coping behaviors in the face of flood disasters were identified, and the effects of these factors were discussed as well. Shenzhen City in China was selected as the study area, in which a questionnaire survey of 339 respondents was carried out in three flood-prone districts. Correlation analysis was conducted to preselect potential influential factors. Then, two linear regression models were established to identify main influential factors and to explore the interaction effects of these factors. The results indicated that age, monthly income, flood experience, trust in government and insurance willingness were main influential factors of protective coping behaviors. Trust in government had the highest positive correlation coefficient, while monthly income and age were negatively associated with protective coping behaviors. The interaction between insurance willingness and monthly income jointly affected protective coping behaviors of the public. The findings of this study could help authorities better understand the public's intention to cope with flood and design effective risk reduction measures, not only for Shenzhen, but also for many other similar cities that facing with the same situation.
\end{abstract}

Keywords: protective coping behaviors; flood disaster; influential factors; questionnaire survey

\section{Introduction}

Currently, the combined impact of various factors, such as abnormal climate and rapid urban expansion, is increasing the risk of flood disasters faced by cities [1], which seriously endangers the safety of people's lives and property [2]. In recent years, the scale of forced evacuation due to flooding has shown a fast-growing trend worldwide. For example, in February 2020, the storm Ciara swept across Europe, causing a short period of traffic disruption, and approximately 14,000 households and companies were affected in Ireland alone. In China, the consequences of flood disasters are even more severe, due to the immature emergency management system. Flood disasters will cause numerous casualties and huge property damage without proper protective coping behaviors. Protective coping behavior is defined as the adjustment process that negative impacts of flood can be mitigated or avoided, according to the definition of the Intergovernmental Panel on Climate Change (IPCC) [3]. Understanding protective coping behaviors of the public and developing effective methods to motivate individuals and households to actively cope with flood disasters are of critical importance in flood risk management. 
Studies about protective coping behaviors in flood disasters began in the 1970s. The research conducted by Huerta and Horton [4], which intended to explain the discrepancy in flood coping behaviors between old and young people, is considered as an early start to explore factors affecting people's protective coping behaviors and has influenced subsequent studies. Reviewing relevant literatures, it can be found that studies on disaster coping behaviors mainly focused on the following aspects:

1. Studying the protective coping behaviors of different subjects. To date, the research subjects of protective coping behaviors include ordinary people $[5,6]$, farmers $[7,8]$, students $[9,10]$ and tourists [11,12].

2. Identifying influential factors of protective coping behaviors. Many influential factors have been explored and analyzed, including sociodemographic factors (such as gender, age, income, education level, etc.), geographic location, previous flood experience, risk perception, trust in government, worry, knowledge of flood. Among sociodemographic factors, age, income and education level are considered to be closely related to protective coping behaviors of the public, and most research results indicate positive relationships [13,14]. Females, as a vulnerable group, are more inclined to take protective measures to deal with flood disasters compared to males, according to Cvetković's [15] study in Serbia. In terms of geographic location, residents living close to flood risk sources are found to have higher intentions to cope with floods [16,17]. When it comes to previous flood experience, personal experience of disasters enhances the general understanding of flood risks [18], and helps victims of floods perceive more severe consequences of future flood disasters, thus leads to stronger intentions to take protective actions $[19,20]$. Due to the development of theoretical framework, such as protection motivation theory, the impact of risk perception on coping behaviors is also widely recognized, and this effect is usually considered to be positive [3,21]. The trust in government, is another crucial influential factor because it determines the effectiveness of the government's risk communication and emergency management [22]. Worry is the most common emotion of the public in the face of floods, which can increase people's intention to cope with flood risks [23,24]. With respect to the knowledge of flood, published literatures [25] believe that it is closely related to protective coping behaviors, more specifically, more knowledge leads to stronger willingness to cope. In summary, current literatures are devoted to exploring the influential factors of protective coping behaviors, but the results vary from study-to-study.

3. Studying and expanding the analytical framework of coping behaviors, such as protection motivation theory $[26,27]$, protective action decision model [28,29], flood-risk precautionary behavior [30], etc. For example, the frame of protection motivation theory includes flood experience, barriers and socio-economic factors as additional factors to explain their influence on coping behaviors [31]. Papagiannaki et al. [30] extend current knowledge of the drivers of flood coping behaviors and predicted flood preparedness intention by proposing flood-risk precautionary behavior theory.

Current studies have explored numerous influencing factors of protective coping behaviors. Some factors are found to have direct effects, but the indirect impact of factors is often ignored. A great number of factors that indirectly affect protective coping behaviors are excluded in most studies. Moreover, studies on protective coping behaviors have a strong regionality, which produce results with local characteristics. Although many influential factors are found to have close relationships with protective coping behaviors, the influence degree of these factors differ a lot due to the variety of study areas and objects. Although structural nonstructural flood control measures are developed in China, it lacks the understanding of flood coping behaviors of the general public, thus the actual effect of the nonstructural measures is attenuated.

In order to discover the factors influencing the public's protective intention to cope with flood disasters and how these factors influence coping behaviors in highly developed cities in China, a 
structured survey study was carried out in five flood-prone communities in three districts in Shenzhen. The data were collected from the proposed Likert-scale questionnaire. Given the importance of protective coping behaviors research in disaster emergency management, this study aims to identify main influential factors of protective coping behaviors and determine to which extent these factors impact the coping behaviors. This study will help government guide residents in Shenzhen to form a more proactive flood response attitude, which can be potentially applied to other cities which are similar to Shenzhen.

\section{Materials and Methods}

\subsection{Study Area}

The study was conducted in Shenzhen because it suffers from severe flood almost every year, leading to huge economic losses and widespread impacts. Meanwhile, Shenzhen is a typical large-scale and well-developed city in China, which is faced with contradictions between urban development and environmental protection. The damage caused by urban expansion to local ecological environment has increased the frequency and severity of natural disasters in Shenzhen, including flood disasters.

Shenzhen-located in the southern region of Guangdong Province, China (as shown in Figure 1) and on the eastern shore of the Pearl River Delta - is a typical coastal developed city. It lies between $113^{\circ} 43^{\prime}-114^{\circ} 38^{\prime}$ east longitude and $22^{\circ} 24^{\prime}-22^{\circ} 52^{\prime}$ north latitude, with a total area of $1996.85 \mathrm{~km}^{2}$. The local climate type is subtropical maritime climate, with an annual average temperature of $22.4{ }^{\circ} \mathrm{C}$ and an annual average sunshine time of $2009.8 \mathrm{~h}$. The annual precipitation is over $1900 \mathrm{~mm}$. In addition, it suffers from 4-5 tropical cyclones (typhoons) on average each year. Shenzhen governs 9 districts including a new district and has a total resident population of 13.025 million according to the census in 2018. Shenzhen is the first Special Economic Zone in China which was established in 1980, and at present it is the core city of the Guangdong-Hong Kong-Macao Greater Bay Area (GBA). Therefore, Shenzhen is regarded as one of the national economic centers of China and the regional GDP in 2019 has reached 26,972 billion $\mathrm{RMB}$, far exceeding other cities.

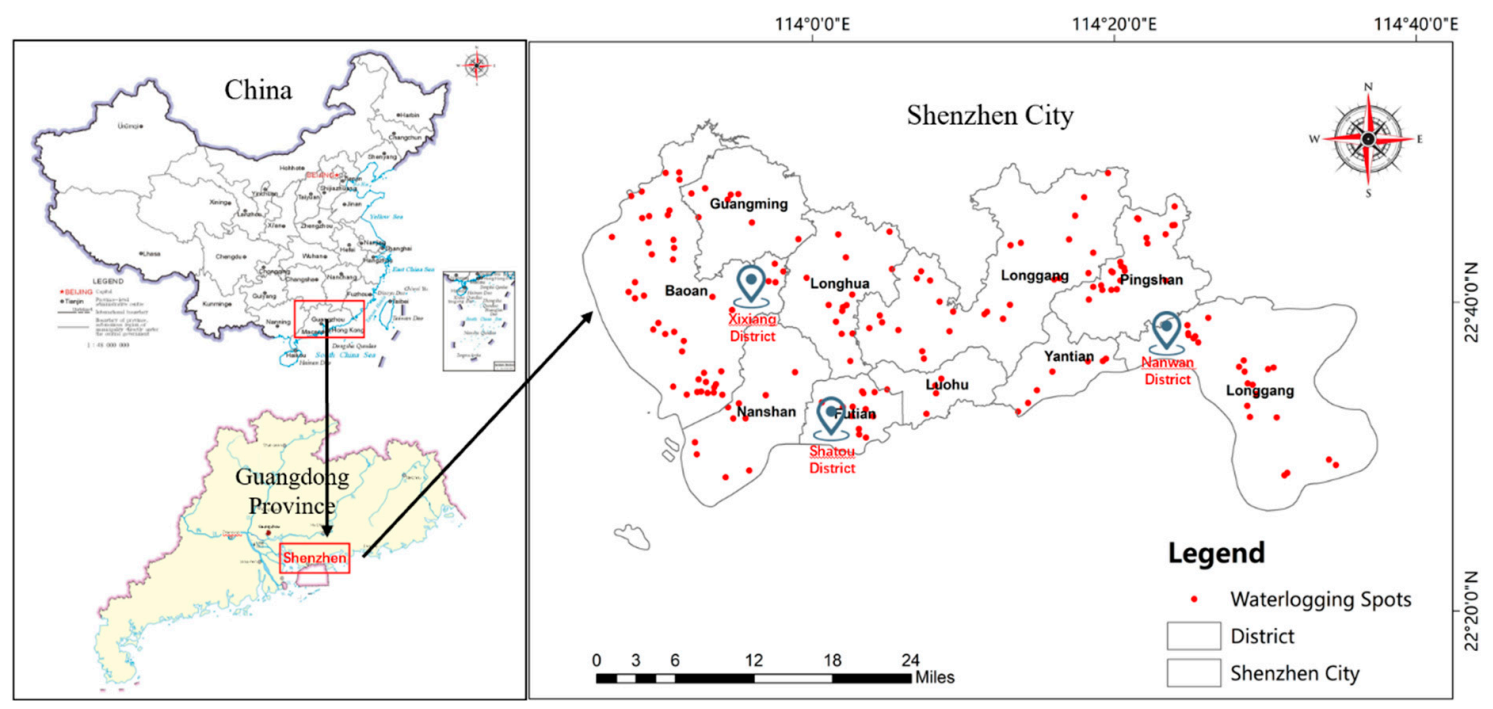

Figure 1. Distribution of research districts in Shenzhen, Guangdong Province, China.

Shenzhen is prone to floods. Due to its coastal location and subtropical maritime climate, the frequency and the intensity of precipitation in the city is relatively high, leading to high risk of flooding. Moreover, Shenzhen is hit by typhoons frequently in the summer, exacerbating the flood risk [32]. In the history of Shenzhen, a great deal of severe flood disasters has occurred. In 2019, the occurrence of short-term heavy rainfall resulted in a sudden flood disaster in Shenzhen, causing 7 deaths and 4 
missing people according to the data from Shenzhen Emergency Management Department. In 2008, a wide-range, intense and long-lasting abnormal precipitation took place, causing severe urban flooding, which affected millions of people and resulted in 8 deaths and 6 missing people. This flood event caused more than 140 waterlogging points in the city and brought about direct economic losses of about 1.2 billion RMB [33]. In 1998, Shenzhen experienced a severe once-in-a-century rainstorm, and the precipitation reached $285-292 \mathrm{~mm}$ in $6 \mathrm{~h}$, resulting in a direct economic loss of 180 million RMB [34]. According to local statistics, it can be found that almost every ten years, a severe flood disaster appears in Shenzhen. As Cui [35] predicted using artificial intelligence algorithm, the economic losses caused by floods in Shenzhen will exceed 257 million RMB by 2020 and 309 million RMB by 2028 . Therefore, there is no doubt that flood risk in Shenzhen is extremely high.

The waterlogging monitoring system for urban water accumulation in Shenzhen is complete, so it is easy to know which areas are vulnerable to waterlogging and flooding. Based on the historical data of waterlogging spots, three districts (Xixiang District, Shatou District, Nanwan District) of Shenzhen under the serious threat of flooding, were chosen to be sampling sites for the survey study. Compared with the other two districts, Nanwan District is more prone to floods, as its low-lying terrain forms waterlogging immediately after short-term heavy rainfalls. Five low-rise communities were selected near easily flooded areas because high-rise residential buildings are less affected by flood disasters.

\subsection{Questionnaire Design}

The purpose of this survey was to understand the public's willingness to respond to flood disasters and to explore potential factors that affect the protective coping behaviors. The questionnaire consisted of 6 sections (as shown in Table 1): sociodemographic factors, risk perception, risk knowledge, risk attitudes, coping capacity and coping behaviors. There were 4 sociodemographic items, gender [15], age [36], education level [37] and monthly income [38], which mainly measured the influence of sociodemographic factors on protective coping behaviors. The second section investigated the public's perception of flood risk [39] and local flooding likelihood [40]. The risk knowledge section, which contained flood experience [41,42] and knowledge of flood damage, aimed to assess the empirical knowledge of the respondents and to investigate their understanding of devastating floods. The next section included trust in government $[30,43]$ and worry [23,30], in order to comprehend the respondents' attitude toward disaster prevention of the government and their concerns about floods. The coping capacity section evaluated the coping ability of respondents, including insurance willingness [44] and familiarity of self-help measures [45]. The last section intended to measure the public's willingness to take protective actions.

Table 1. Definition of measurement and influential factors of protective coping behaviors.

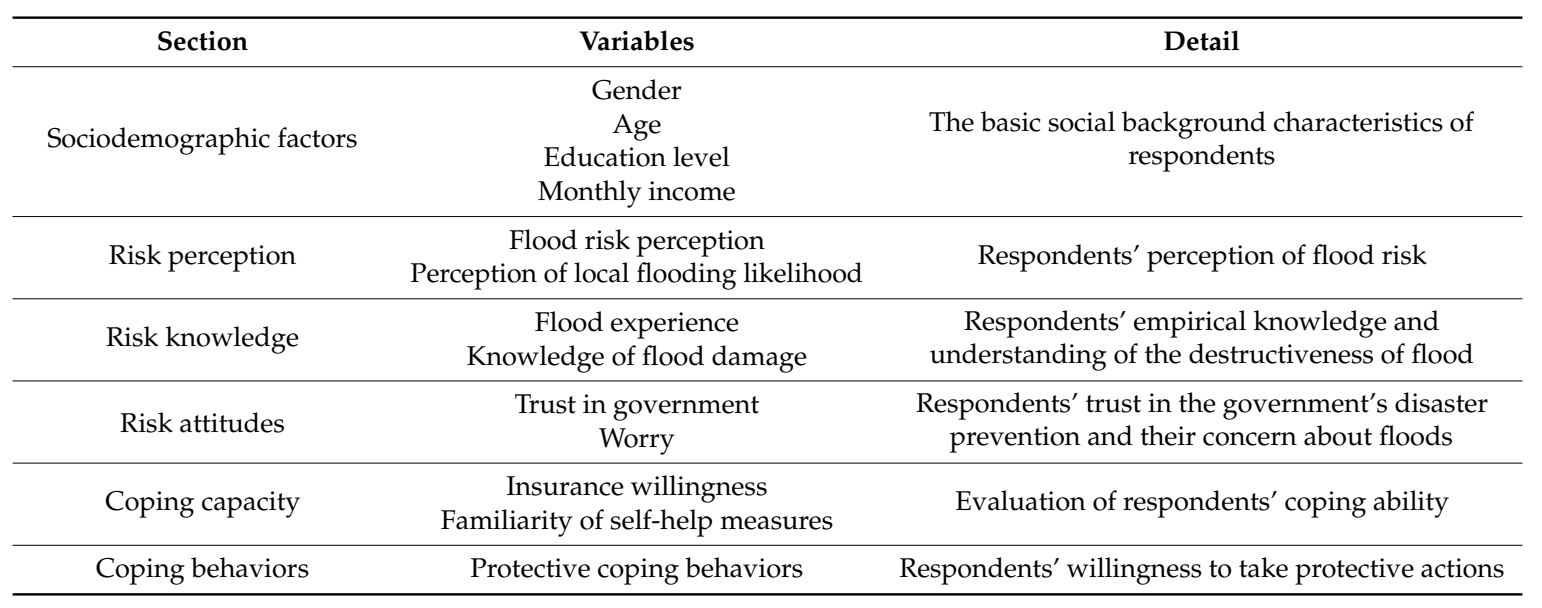

The structured questionnaire took the form of a 5-point Likert scale to facilitate the quantification of the data. The Likert scale is widely used in the field of psychology and social science to measure opinions 
or attitudes of respondents [46]. In order to eliminate misunderstandings about the questions, a small group of people with different education background were selected to fill out the questionnaire before the formal survey, and the items of the survey were modified to be more easily understood by respondents based on their feedback on the questions. Additionally, the reliability of the questionnaire was preliminarily tested during the pilot study, in order to ensure the overall reliability of the questionnaire.

\subsection{Data Collection}

Data were collected using a face-to-face questionnaire survey conducted from 6th July to 12th July 2019. The questionnaires were mainly distributed by graduate students who had basic knowledge of natural-disaster emergency management and the background of questionnaire design and collection. In order to ensure the number of valid questionnaires, the distribution process was led by community managers. However, the collection process adhered to the principle of voluntariness. To avoid distortion of the questionnaire data, this study did not force any respondents to fill out the questionnaire in order. Respondents had the right to refuse to participate or withdraw from the survey at any time. Moreover, a souvenir was given to each respondent after completing the questionnaire as an encouragement to their participation. The number of samples selected in each district was in accordance with the population distribution of the three target districts (the ratio of Xixiang District, Shatou District and Nanwan District is approximately 1:1:2). Eventually, a total of 400 questionnaires were distributed in the study area and $339(84.75 \%)$ valid questionnaires were obtained excluding unqualified questionnaires.

\subsection{Statistical Analysis Method}

The process of the statistical analysis in this study can be considered as a three-stage approach. First of all, descriptive statistics were calculated to summarize the general background characteristics of the respondents (including gender, age, education level, income) and to analyze the basic distribution of the data.

Next, correlation analysis was conducted to identify whether the hypothesized influence factors had a significant impact on protective coping behaviors. The correlation coefficients of these influential factors were calculated through Equations (1) and (2), in order to examine their degrees of influence on protective coping behaviors.

$$
\begin{gathered}
\operatorname{Cov}=\mathrm{E}[X Y]-E[X] E[Y] \\
R(X, Y)=\frac{\operatorname{Cov}(X, Y)}{\sqrt{\operatorname{Var}[X] \cdot \operatorname{Var}[Y]}}
\end{gathered}
$$

In Equation (1), $\mathrm{E}[X], \mathrm{E}[Y]$ and $\mathrm{E}[\mathrm{XY}]$ stand for the expected values of $X, Y$ and the product of $X$ and $Y$, respectively. In Equation (2), $\operatorname{Cov}(X, Y)$ denotes the covariance of $X$ and $Y$, while $\operatorname{Var}[X]$ and $\operatorname{Var}[Y]$ represent the variances of $X$ and $Y$, respectively.

Finally, regression analysis was conducted to determine whether there was a linear relationship between the influential factors and the protective coping behaviors. The factors of the multiple regression models were selected based on the findings of the correlation analysis. Two regression models were established and compared in order to identify main influential factors as well as interaction terms.

Both the correlation analysis and regression analysis were conducted using a significance level of 0.05 , in other words, factors were considered to have an impact on protective coping behaviors when the $p$-values of these factors were less than $0.05[38,47]$. All data in this study were analyzed using SPSS statistics software (Version 22.0, SPSS, Inc., Chicago, IL, USA). 


\section{Results}

\subsection{Characteristics of Respondents}

A total of 339 valid questionnaires were obtained in this study. According to the reliability test of the questionnaire data, the Cronbach's alpha coefficient reached 0.811, which indicated good consistency of the scale [48]. Table 2 showed the sociodemographic attributes of the respondents in Shenzhen on four basic aspects: gender, age, education level and monthly income.

Table 2. Sociodemographic attributes of respondents.

\begin{tabular}{ccccc}
\hline Variable & Shenzhen (Total) & Xixiang District & Shatou District & Nanwan District \\
\hline $\begin{array}{c}\text { Gender } n(\%) \\
\text { Male }\end{array}$ & $172(50.74 \%)$ & $44(49.44 \%)$ & $37(51.39 \%)$ & $91(51.12 \%)$ \\
Female & $167(49.26 \%)$ & $45(50.56 \%)$ & $35(48.51 \%)$ & $87(48.88 \%)$ \\
\hline Age $n(\%)$ & & & \\
$<20$ years old & $30(8.84 \%)$ & $6(6.74 \%)$ & $15(20.83 \%)$ & $9(5.06 \%)$ \\
$20-29$ years old & $152(44.84 \%)$ & $28(31.46 \%)$ & $33(45.83 \%)$ & $91(51.12 \%)$ \\
$30-39$ years old & $95(28.02 \%)$ & $30(33.71 \%)$ & $13(18.06 \%)$ & $52(29.21 \%)$ \\
$40-49$ years old & $39(11.51 \%)$ & $16(17.98 \%)$ & $7(9.72 \%)$ & $16(8.99 \%)$ \\
$\geq 50$ years old & $23(6.79 \%)$ & $9(10.11 \%)$ & $4(5.56 \%)$ & $9(5.62 \%)$ \\
\hline Education level $n(\%)$ & & & & \\
Middle school or & $102(30.09 \%)$ & $40(44.95 \%)$ & $21(29.17 \%)$ & $49(27.53 \%)$ \\
below & $123(36.28 \%)$ & $34(38.20 \%)$ & $32(44.44 \%)$ & $51(28.65 \%)$ \\
High school & $114(33.63 \%)$ & $15(16.85 \%)$ & $19(26.39 \%)$ & $78(43.82 \%)$ \\
Bachelor's or higher & & & \\
\hline Monthly income $n(\%)$ & $191(56.34 \%)$ & $51(57.30 \%)$ & $31(43.06 \%)$ & $109(61.24 \%)$ \\
$<¥ 5000$ & $110(32.45 \%)$ & $20(22.47 \%)$ & $32(44.44 \%)$ & $58(32.58 \%)$ \\
$¥ 5000-9999$ & $26(7.67 \%)$ & $16(17.98 \%)$ & $4(5.56 \%)$ & $6(3.37 \%)$ \\
$¥ 10,000-19,999$ & $7(2.06 \%)$ & $2(2.25 \%)$ & $3(4.17 \%)$ & $2(1.12 \%)$ \\
$¥ 20,000-29,999$ & $5(1.48 \%)$ & $0(0.00 \%)$ & $2(2.77 \%)$ & $3(1.69 \%)$ \\
$\geq ¥ 30,000$ & &
\end{tabular}

Among the 339 respondents, the proportion of male (50.74\%) and female $(49.26 \%)$ were rather close. For each district, the largest gap between male and female was less than $3 \%$, indicating that the sample size was balanced in terms of gender. The majority (approximately 85\%) of the respondents aged from 20 to 49 years old, more specifically, the proportions of people in their 20's, 30's and 40's were $44.84 \%, 28.02 \%$ and $11.51 \%$, respectively. With respect to education level, none of the respondents held a master's degree or higher and high school education (36.28\%) accounted for the most. In detail, most respondents in Xixiang District had middle school or below education, while most respondents held high school degree in Shatou District and bachelor's degree in Nanwan District. Regarding monthly income, $88.79 \%$ of respondents made less than 10,000 RMB per month and only $3.54 \%$ of the respondents earned more than 20,000 RMB. The distribution of income in the three communities was basically consistent with the overall population. On the whole, the respondents in the three districts were representative of the general population.

\subsection{Protective Coping Behaviors in Three Districts}

Among the 339 samples, 89 respondents (26.25\%) were from Xixiang District, 72 (21.24\%) were from Shatou District and 178 (52.51\%) were from Nanwan District, which was consistent with the population distribution of the three districts (the population of each district was approximately $66,000,63,000$ and 122,000, respectively, about 1:1:2). Table 3 showed the descriptive statistics of the respondents' intentions to take protective coping behaviors in three areas. 
Table 3. Comparison of protective coping behavior intention between different districts.

\begin{tabular}{ccccc}
\hline District & Mean & $\mathbf{N}$ & Std. Deviation & Difference from Mean \\
\hline Xixiang & 3.640 & 89 & 1.359 & -0.110 \\
Shatou & 3.710 & 72 & 1.168 & -0.050 \\
Nanwan & 3.850 & 178 & 1.176 & 0.090 \\
Total & 3.760 & 339 & 1.225 & - \\
\hline
\end{tabular}

As shown in Table 3, the overall mean score of the 339 respondents' intentions to take protective coping behaviors in Shenzhen was $3.76(\mathrm{SD}=1.225)$ on a scale of $1-5$. This means that respondents in Shenzhen had a slightly higher than medium level of coping behavior intention during flood disasters, which further indicated a greater risk of potential flood loss in Shenzhen. Nanwan District had the highest level of coping behavior intention, with mean of 3.85 ( $\mathrm{SD}=1.176$ ), exceeding the grand mean, which could be explained by being one of the most severe flood-prone areas in Shenzhen. On the contrary, the levels of coping behavior intention of Xixiang District and Shatou District were lower than average, with mean of $3.71(\mathrm{SD}=1.168)$ and $3.64(\mathrm{SD}=1.359)$, respectively. However, it was found that the $p$-values of the pairwise comparisons were all greater than 0.05 (Xixiang District and Shatou District: $\mathbf{t}(336)=-0.350, p=0.727$; Xixiang District and Nanwan District: $t(336)=-1.307, p$ $=0.192$; Shatou District and Nanwan District: $\mathrm{t}(336)=-0.818, p=0.414)$, which indicated that the differences of the levels of protective coping behaviors among the three districts was insignificant.

\subsection{Correlation between Factors}

The purpose of the correlation analysis between each influential factors and protective coping behaviors was twofold: (a) to verify whether the influential factors in Table 1 were associated with protective coping behaviors; (b) to find out how these factors were correlated with protective coping behaviors.

As shown in Table 4, gender, perception of local flooding likelihood and monthly income proved to be unrelated to protective coping behaviors, because the $p$-values of these factors were all greater than 0.05 and the correlation coefficients were all less than 0.1 . Correlation analysis failed to provide evidence for the impact of the gender and perception of local flooding likelihood on protective coping behaviors of the public. Moreover, monthly income was also considered to be independent from protective coping behaviors through the correlation analysis. This result was similar to the findings of Meyer et al. [38], which discovered that there was no significant correlation between income and evacuation intention.

Age, education level, flood risk perception, flood experience, knowledge of flood damage, trust in government, worry, insurance willingness, familiarity of self-help measures passed the correlation test, which indicated that changes in these factors will affect protective coping behaviors when people are faced with flood disasters. Among these factors, only age was negatively correlated with protective coping behaviors - that was, the willingness to cope protectively diminished as people got older. Except for age, all the other factors were positively correlated with protective coping behaviors. 
Table 4. Results of correlation analysis between influential factors and protective coping behaviors.

\begin{tabular}{|c|c|c|c|c|c|c|c|c|c|c|c|c|c|}
\hline & РCB & Gen & Age & EL & MI & FRP & PLFL & FE & KFD & TG & Wor & IW & FSM \\
\hline РCB & 1 & & & & & & & & & & & & \\
\hline Gen & 0.055 & 1 & & & & & & & & & & & \\
\hline Age & $-0.155^{* *}$ & -0.070 & 1 & & & & & & & & & & \\
\hline EL & $0.115^{* *}$ & -0.007 & $-0.299 * *$ & 1 & & & & & & & & & \\
\hline MI & -0.015 & -0.050 & -0.031 & $0.122 *$ & 1 & & & & & & & & \\
\hline FRP & $0.156^{* *}$ & -0.127 * & 0.009 & $0.227^{* *}$ & 0.072 & 1 & & & & & & & \\
\hline PLFL & -0.069 & 0.063 & 0.070 & 0.069 & -0.029 & $0.145^{* *}$ & 1 & & & & & & \\
\hline FE & $0.334^{* *}$ & 0.045 & -0.119 * & $0.158^{* *}$ & 0.101 & $0.305^{* *}$ & 0.071 & 1 & & & & & \\
\hline KFD & $0.180^{* *}$ & -0.065 & 0.036 & 0.121 * & 0.068 & $0.386^{* *}$ & 0.074 & $0.384 * *$ & 1 & & & & \\
\hline TG & $0.403^{* *}$ & -0.029 & -0.054 & 0.045 & 0.038 & $0.195^{* *}$ & -0.072 & $0.321^{* *}$ & $0.259 * *$ & 1 & & & \\
\hline Wor & $0.148^{* *}$ & 0.117 * & $0.117^{*}$ & 0.038 & 0.089 & 0.043 & $0.131 *$ & $0.155^{* *}$ & 0.160 ** & 0.126 * & 1 & & \\
\hline IW & $0.175^{* *}$ & 0.027 & $-0.215^{* *}$ & $0.329^{* *}$ & $0.143^{* *}$ & $0.202^{* *}$ & -0.006 & $0.247^{* *}$ & $0.177^{* *}$ & $0.198^{* *}$ & $0.163^{* *}$ & 1 & \\
\hline FSM & $0.235^{* *}$ & -0.053 & 0.060 & 0.068 & 0.034 & $0.465^{* *}$ & $0.146^{* *}$ & $0.371^{* *}$ & $0.545^{* *}$ & $0.293 * *$ & 0.129 * & 0.094 & 1 \\
\hline
\end{tabular}

Note: PCB—protective coping behaviors; Gen—gender; EL—education level; MI—monthly income; FRP—flood risk perception; PLFL—perception of local flooding likelihood; FE—flood experience; KFD—knowledge of flood damage; TG—-trust in government; Wor—worry; IW—insurance willingness; FSM-familiarity of self-help measures. ${ }^{* *}$ represents that the correlation is significant at the 0.01 level (2-tailed); ${ }^{*}$ represents that the correlation is significant at the 0.05 level (2-tailed). 
Figure 2 intuitively showed the correlations between each factor and protective coping behaviors, from which we could tell the ranking of the degree of correlation. In terms of the correlation degree, the five factors that had the greatest influences on protective coping behaviors were: trust in government $(r=0.403)$, flood experience $(r=0.334)$, familiarity of self-help measures $(r=0.235)$, knowledge of flood damage $(r=0.180)$, insurance willingness $(r=0.175)$. The correlation coefficients of trust in government and flood experience were greater than 0.3 , indicating that they were the key factors affecting coping behaviors of the public. Additionally, the impact of other factors on protective coping behaviors was not neglectable. The correlations with familiarity of self-help measures, knowledge of flood damage, insurance willingness, flood risk perception, worry and education level were 0.235 , $0.180,0.175,0.156,0.148$ and 0.115 , respectively. A weak correlation between flood risk perception and protective coping behaviors was found in this study.

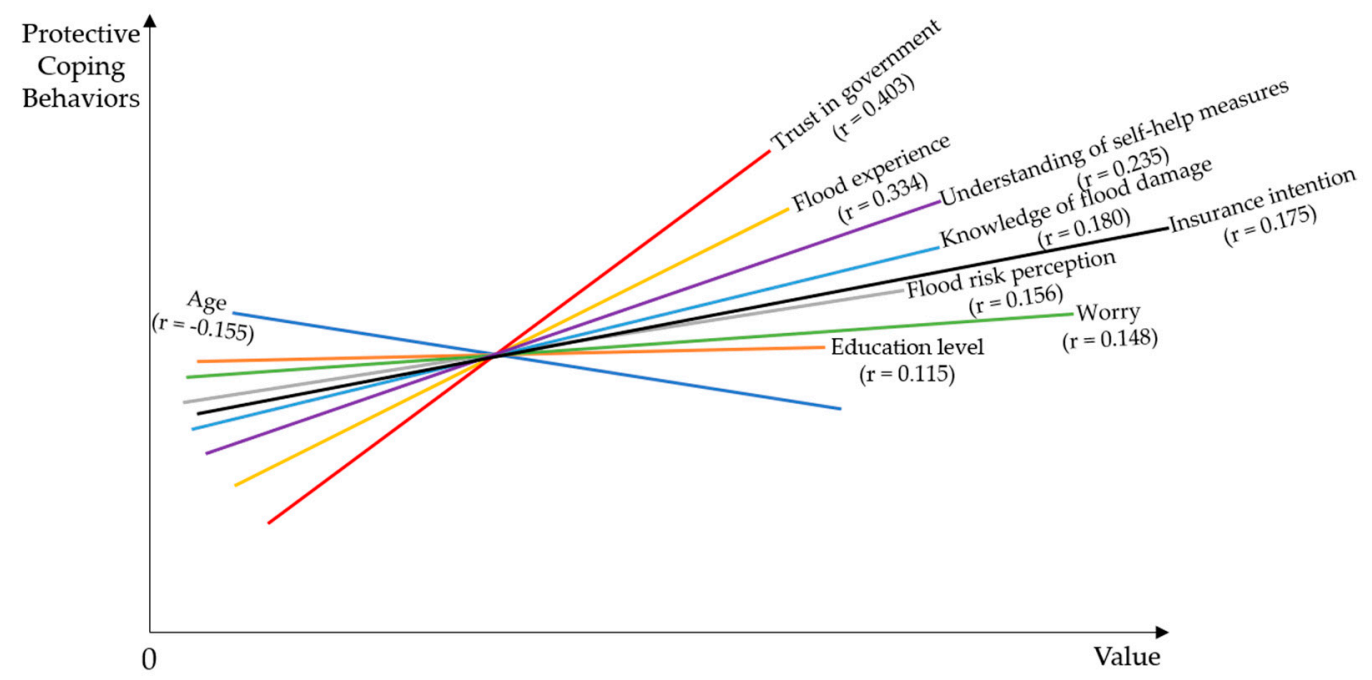

Figure 2. Schematic diagram of correlation between factors.

\subsection{Influential Factors of Protective Coping Behaviors}

(1) Linear regression model

Regression analysis was carried out to explore the linear relationships between the influential factors and protective coping behaviors of the residents in Shenzhen. Initially, a multiple regression model which contained 9 influential factors was established with a significance level of 0.05 .

Factors that passed the correlation test (age, education level, flood risk perception, flood experience, knowledge of flood damage, trust in government, worry, insurance willingness and familiarity of self-help measures) were considered to be closely related to protective coping behaviors. Therefore, all these factors were included in the initial multiple linear regression model. The results showed that this model was significant $(F(9,329)=11.459, p=0.000)$ to predict protective coping behaviors. The adjusted R-square was 0.218 , which means $21.8 \%$ variation in the dependent variable (protective coping behaviors) could be explained by the regression.

As shown in Table 5, age $(p=0.010)$, flood experience $(p=0.002)$ and trust in government $(p=0.000)$ were regarded as main influential factors of protective coping behaviors in this model, because the significance level of these three factors were all less than 0.05 . However, the other variables (education, flood risk perception, knowledge of flood damage, worry, insurance willingness and familiarity of self-help measures) were insignificant in predicting protective coping behaviors. Nevertheless, the influence of these factors on protective coping behaviors was still worth discussing. 
Table 5. Coefficients of the linear regression model.

\begin{tabular}{ccccc}
\hline Regression Model & $\mathbf{B}$ & Std. Error & $\mathbf{t}$ & $p$-Value \\
\hline Constant & 1.569 & 0.382 & 4.108 & $0.000^{* *}$ \\
Age & -0.162 & 0.063 & -2.583 & $0.010^{* *}$ \\
Education level & 0.031 & 0.081 & 0.386 & 0.700 \\
Flood risk perception & 0.003 & 0.062 & 0.044 & 0.965 \\
Flood experience & 0.172 & 0.055 & 3.123 & $0.002 * *$ \\
Knowledge of flood damage & -0.034 & 0.067 & -0.515 & 0.607 \\
Trust in government & 0.330 & 0.057 & 5.788 & $0.000 * *$ \\
Worry & 0.084 & 0.048 & 1.742 & 0.082 \\
Insurance willingness & 0.014 & 0.046 & 0.310 & 0.756 \\
Familiarity of self-help measures & 0.093 & 0.065 & 1.433 & 0.153 \\
\hline
\end{tabular}

Note: ${ }^{* *}$ represents that the correlation is significant at the 0.01 level.

The regression coefficient (B) measured the linear effect level of independent variables on coping behaviors. The regression coefficients of trust in government, 0.330 , was the highest in this model, followed by flood experience, which was 0.172 . The regression coefficient of age was negative $(\mathrm{B}=$ $-0.162)$, which was consistent with the results from the correlation analysis. Among the insignificant factors, the regression coefficients of worry $(B=0.084)$ and familiarity of self-help measures $(B=0.093)$ were nonignorable.

To summarize, through the multiple linear regression model, three main influential factors of protective coping behaviors, age, flood experience and trust in government, were identified. Therefore, when studying coping behaviors of the public, these three factors should be taken into account. Even though the other factors were found to be insignificant in this linear regression, it did not mean that they had no effect on coping behaviors. In the next section, the interaction effects of these variables were studied, instead of simply excluding them from the linear model.

(2) Linear regression model with interaction

Although the linear regression model in Section 3.3 only identified three major influential factors of protective coping behaviors, this model ignored the interaction effects of these factors. It did not necessarily suggest that insignificant variables should be eliminated from the linear model, and they might potentially interact with other variables to jointly influence coping behaviors. Therefore, this study attempted to explore all possible linear models with interactions. An interaction term was the product of two different variables, and only the interaction between monthly income and insurance willingness were presented.

Compared to the initial linear regression model above, the new model considering interaction effect improved the goodness of fit (adjusted R-square $=0.2261$ ), indicating $0.81 \%$ more of the variability in the protective coping behaviors could be explained by including the interaction between monthly income and insurance willingness in the model. As shown in Table 6, the interaction between monthly income and insurance willingness was significant $(p=0.027)$. This indicated that monthly income and insurance willingness jointly affected the protective coping behaviors, even though neither of them was significant in the previous model. This finding agreed with the significant correlation coefficient between monthly income and insurance willingness (as shown in Table 4) which suggested that these two factors were closely associated. 
Table 6. Coefficients of Model with interactive variables.

\begin{tabular}{ccccc}
\hline Model with Interactive Variables & B & Std. Error & $\mathbf{t}$ & $p$-Value \\
\hline Constant & 2.535 & 0.417 & 6.081 & $0.000^{* *}$ \\
Age & -0.157 & 0.059 & -2.653 & $0.008^{* *}$ \\
Trust in government & 0.360 & 0.056 & 6.499 & $0.000^{* *}$ \\
Flood experience & 0.205 & 0.051 & 4.044 & $0.000^{* *}$ \\
Monthly income & -0.438 & 0.174 & -2.512 & $0.012^{*}$ \\
Insurance willingness & -0.142 & 0.091 & -1.562 & 0.119 \\
Monthly income* insurance willingness & 0.109 & 0.049 & 2.221 & $0.027^{*}$ \\
\hline
\end{tabular}

Note: ${ }^{* *}$ represents that the correlation is significant at the 0.01 level; * represents that the correlation is significant at the 0.05 level.

In order to further explore the interaction effect between monthly income and insurance willingness, other factors in the model, age, trust in government and flood experience, were fixed as constant. The values of age (mode $=2)$, trust in government $($ mode $=3)$, flood experience (mode $=5)$ were set to be their modes. As demonstrated in Figure 3, when the monthly income of the respondents was less than $5000 \mathrm{RMB}$, their intentions to cope protectively decreased as their insurance willingness increased. On the contrary, when monthly income was more than $5000 \mathrm{RMB}$, there was a positive relationship between protective coping behaviors and insurance willingness. The higher the income level was, the greater the positive effect of insurance intention on protective coping behaviors. In other words, the willingness to take coping behaviors of high-income individuals was stronger when they had higher insurance willingness, while that of low-income people was stronger when they had lower insurance willingness.

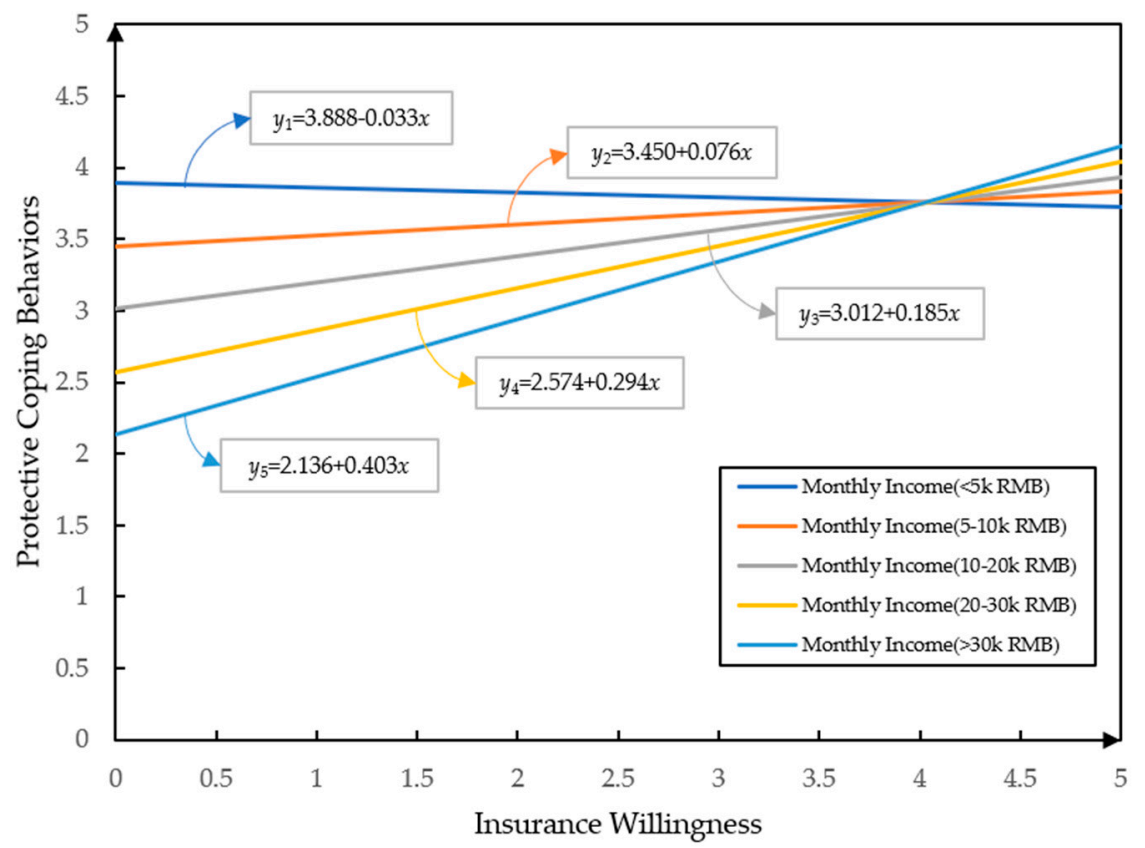

Figure 3. The interaction effect of monthly income and insurance willingness. Note: $y$ represents protective coping behaviors, $x$ represents insurance willingness.

\section{Discussion}

This study aimed to explore which factors have significant impact on protective coping behaviors. Age, education level, flood risk perception, flood experience, knowledge of flood damage, trust in government, worry, insurance willingness, and familiarity of self-help measures were found to be correlated with protective coping behaviors of the residents in Shenzhen. In addition, we also found 
out that main influential factors, such as age, trust in government and flood experience, had a strong linear relationship with coping behaviors, which was consistent with most findings from studies in other countries, for instance, Thailand, New Zealand, etc. [49-51].

More important, factors that were not highly correlated with protective coping behaviors might also affect coping behaviors. For example, monthly income and insurance willingness were found to be insignificant in the initial regression model, but after including the interaction term of these two factors in the second regression model, their impact on protective coping behaviors became significant. This could be explained by similar studies, which had found that monthly income and insurance willingness were regarded as nonnegligible factors of coping behaviors [47,52]. Therefore, when screening factors, correlation analysis or simple linear analysis were not sufficient to determine the potential influence of factors. In other words, the factors could not be excluded only based on the results of these analyses. The interaction effects of factors needed to be further taken into account.

The structural equation model (SEM) is a common tool in other studies to explore the complicated relationships among factors. For example, a similar study conducted by Huang et al. [53], established a SEM to explore the relationship between influential factors and protective coping behaviors. Huang' study found that protective coping behaviors of the public were indirectly affected by sociodemographic factors like age and monthly income, which suggested that sociodemographic factors might interact with other influential factors on protective coping behaviors. This study proposed another approach to explore the interaction effects between variables using linear regression, and similar results were discovered. Monthly income-as one of the typical sociodemographic factors-jointly affected the protective coping behaviors with insurance willingness. On top of this, the potential interaction of the effects of other factors on protective coping behaviors could be further investigated using the proposed method.

In this study, only three flood-prone districts in Shenzhen were selected. Therefore, these findings only represented the protective coping behaviors of people under serious threats of flooding. In the future, more samples will be selected from the overall population in order to reach more general conclusions. The questionnaire survey was carried out anonymously to ensure the objectivity of the results. However, some illiterate participants finished the questionnaires with the assistance of our volunteers, thus they might feel uncomfortable sharing their true opinions, especially government-related questions, leading to biased ratings of these items. Furthermore, because there is no standardized questionnaire of protective coping behaviors, this study may have omissions in the selection of influencing factors. A standardized questionnaire should to be developed and validated in future studies. Nonetheless, findings of this research could help decision-makers in the government to formulate effective communication strategies and flood risk reduction policies. In the future, we will include more samples and explore the coping behaviors of the public in depth from a social point of view.

\section{Conclusions}

In summary, five flood-prone communities from three districts in Shenzhen were investigated and more than 300 valid questionnaires were analyzed. First, the overall level of protective coping behaviors of respondents in the three districts was analyzed. Then, the correlation analysis and regression analysis were conducted to determine which factors influence protective coping behaviors of the public in Shenzhen. The key findings of this study are:

1. Respondents' protective coping behaviors in Shenzhen were above the medium level with overall mean of 3.76 (on a scale from 1 to 5). More specifically, Nanwan District had the highest level of protective coping behaviors, with mean of 3.85, and Xixiang District had the lowest level of protective coping behaviors, with mean of 3.64;

2. Age, flood experience, trust in government, monthly income and insurance willingness were found to be closely associated with protective coping behaviors in Shenzhen. Trust in government $(B=0.360)$ had the greatest positive impact, followed by flood experience $(B=0.205)$. Age 
$(\mathrm{B}=-0.157)$ and monthly income $(\mathrm{B}=-0.438)$ were negatively associated with protective coping behaviors;

3. Monthly income and insurance intention had insignificant direct effect on protective coping behaviors. However, the interaction effect of these two factors on protective coping behaviors was significant, which indicated that insurance willingness and monthly income $(B=0.109)$ jointly affect the protective coping behaviors.

This study concluded that age, flood experience, trust in government, monthly income and insurance willingness were the main influential factors of protective coping behaviors of residents in Shenzhen. We conducted a 3-step approach to explore the interaction between variables using linear model and explored the interaction of monthly income and insurance willingness. These findings can help authorities better understand the public's intention to cope with flood disasters and design effective risk reduction measures, not only for Shenzhen, but also for many similar cities in China faced with the same situation and dilemma.

Author Contributions: Conceptualization, Y.Y. and J.H.; formal analysis, W.C. and Y.Y.; funding acquisition, J.H. and G.L.; investigation, W.C., J.H. and D.S.; methodology, W.C. and Y.Y.; project administration, J.H. and G.L.; resources, D.S.; supervision, J.H.; writing—original draft, W.C.; writing—review \& editing, W.C., Y.Y. and J.H. All authors have read and agree to the published version of the manuscript.

Funding: This research was funded by National Key Research and Development Program of China (No. 2017YFC1502603) and National Natural Science Foundation of China (No. 71601070).

Acknowledgments: We would like to express our gratitude to the Shenzhen City District office and street office for the authorization and support to conduct the study. Finally, we are grateful all the investigators and respondents who participated in the survey.

Conflicts of Interest: The authors declare no conflict of interest.

\section{References}

1. Lee, E.H.; Kim, J.H. Development of resilience index based on flooding damage in urban areas. Water 2017, 9, 428. [CrossRef]

2. Wang, W.W.; Wang, Q.; Lin, H.; Gong, D.J.; Zhang, S.W. Summarization and prospection for the studies on China's urban water logging. Urban Probl. 2015, 10, 24-28.

3. Bubeck, P.; Botzen, W.J.W.; Kreibich, H.; Aerts, J.C.J.H. Detailed insights into the influence of flood-coping appraisals on mitigation behaviour. Glob. Environ. Chang. 2013, 23, 1327-1338. [CrossRef]

4. Huerta, F.; Horton, R. Coping behavior of elderly flood victims. Gerontologist 1978, 18, 541-546. [CrossRef]

5. Abbas, A.; Amjath-Babu, T.S.; Kächele, H.; Usman, M.; Amjed Iqbal, M.; Arshad, M.; Adnan Shahid, M.; Müller, K. Sustainable survival under climatic extremes: Linking flood risk mitigation and coping with flood damages in rural Pakistan. Environ. Sci. Pollut. Res. 2018, 25, 32491-32505. [CrossRef]

6. De Dominicis, S.; Crano, W.D.; Cancellieri, U.G.; Mosco, B.; Bonnes, M.; Hohman, Z.; Bonaiuto, M. Vested interest and environmental risk communication: Improving willingness to cope with impending disasters. J. Appl. Soc. Psychol. 2014, 44, 364-374. [CrossRef]

7. Nazir, A.; Li, G.; Sheikh, M.J.; Zhou, X.; Humayoon, A.; Rizwan, M.; Akhtar, S. Farmers' Perceptions of Risk Sources and Risk Coping Strategies in Pakistan. J. Anim. Plant Sci. 2018, 28, 889-906.

8. Singh, O.; Singh, H. The response of farmers to the flood hazard under rice-wheat ecosystem in Somb basin of Haryana, India: An empirical study. Nat. Hazards 2015, 75, 795-811. [CrossRef]

9. Seyle, D.C.; Widyatmoko, C.S.; Silver, R.C. Coping with natural disasters in Yogyakarta, Indonesia: A study of elementary school teachers. Sch. Psychol. Int. 2013, 34, 387-404. [CrossRef]

10. Li, J.Y. Evaluation on public risk perception: A case study on college students. J. Nat. Disaster 2005, 14, 153-156.

11. Wu, L.; Zhang, J.; Lu, Q.; Rahman, A.B.M.S. Tourist adaptation behavior in response to climate disasters in Bangladesh. J. Sustain. Tour. 2017, 25, 217-233. [CrossRef]

12. Kajan, E.; Saarinen, J. Tourism, climate change and adaptation: A review. Curr. Issues Tour. 2013, 16, 167-195. [CrossRef] 
13. Tongtham, A.; Kerdmongkol, P.; Amnatsatsue, K.; Jirapongsuwan, A.; Nanthamongkolchai, S. Flood preparedness behavior among older people with chronic diseases in a flood prone area of Thailand. E. Asian J. Trop. Med. 2019, 50, 786-792.

14. Ajibade, I.; Armah, F.A.; Kuuire, V.Z.; Luginaah, I.; McBean, G.; Tenkorang, E.Y. Assessing the bio-psychosocial correlates of flood impacts in coastal areas of Lagos, Nigeria. J. Environ. Plan. Manag. 2015, 58, 445-463. [CrossRef]

15. Cvetković, V.; Roder, G.; Öcal, A.; Tarolli, P.; Dragićević, S. The Role of Gender in Preparedness and Response Behaviors towards Flood Risk in Serbia. Int. J. Environ. Res. Public Health 2018, 15, 2761. [CrossRef]

16. Botzen, W.J.W.; Aerts, J.C.J.H.; van den Bergh, J.C.J.M. Willingness of homeowners to mitigate climate risk through insurance. Ecol. Econ. 2009, 68, 2265-2277. [CrossRef]

17. Tonn, G.; Guikema, S.; Zaitchik, B. Simulating Behavioral Influences on Community Flood Risk under Future Climate Scenarios. Risk Anal. 2020, 40, 884-898. [CrossRef] [PubMed]

18. Pagneux, E.; Gisladottir, G.; Jonsdottir, S. Public perception of flood hazard and flood risk in Iceland: A case study in a watershed prone to ice-jam floods. Nat. Hazards 2011, 58, 269-287. [CrossRef]

19. Zaalberg, R.; Midden, C.; Meijnders, A.; McCalley, T. Prevention, Adaptation, and Threat Denial: Flooding Experiences in the Netherlands. Risk Anal. 2009, 29, 1759-1778. [CrossRef]

20. Poussin, J.K.; Botzen, W.J.W.; Aerts, J.C.J.H. Factors of influence on flood damage mitigation behaviour by households. Environ. Sci. Policy 2014, 40, 69-77. [CrossRef]

21. De Dominicis, S.; Fornara, F.; Ganucci Cancellieri, U.; Twigger-Ross, C.; Bonaiuto, M. We are at risk, and so what? Place attachment, environmental risk perceptions and preventive coping behaviours. J. Environ. Psychol. 2015, 43, 66-78. [CrossRef]

22. Terpstra, T. Emotions, Trust, and Perceived Risk: Affective and Cognitive Routes to Flood Preparedness Behavior. Risk Anal. 2011, 31, 1658-1675. [CrossRef] [PubMed]

23. Haney, T.J. Move out or dig in? Risk awareness and mobility plans in disaster-affected communities. J. Contingencies Crisis Manag. 2019, 27, 224-236. [CrossRef]

24. Aspinwall, L.G.; Sechrist, G.B.; Jones, P.R. Expect the best and prepare for the worst: Anticipatory coping and preparations for Y2K. Motiv. Emot. 2005, 29, 357-388. [CrossRef]

25. Samah, A.A.; Zaremohzzabieh, Z.; Shaffril, H.A.M.; D'Silva, J.L.; Kamarudin, S. Researching natural disaster preparedness through health behavioral change models. Am. J. Disaster Med. 2019, 14, 51-63.

26. Dittrich, R.; Wreford, A.; Butler, A.; Moran, D. The impact of flood action groups on the uptake of flood management measures. Clim. Chang. 2016, 138, 471-489. [CrossRef]

27. Schlef, K.E.; Kaboré, L.; Karambiri, H.; Yang, Y.C.E.; Brown, C.M. Relating perceptions of flood risk and coping ability to mitigation behavior in West Africa: Case study of Burkina Faso. Environ. Sci. Policy 2018, 89, 254-265. [CrossRef]

28. Liu, Y.; Ouyang, Z.; Cheng, P. Predicting consumers' adoption of electric vehicles during the city smog crisis: An application of the protective action decision model. J. Environ. Psychol. 2019, 64, 30-38. [CrossRef]

29. Strahan, K.; Watson, S.J. The protective action decision model: When householders choose their protective response to wildfire. J. Risk Res. 2019, 22, 1602-1623. [CrossRef]

30. Papagiannaki, K.; Kotroni, V.; Lagouvardos, K.; Papagiannakis, G. How awareness and confidence affect flood-risk precautionary behavior of Greek citizens: The role of perceptual and emotional mechanisms. Nat. Hazards Earth Syst. Sci. 2019, 19, 1329-1346. [CrossRef]

31. Twerefou, D.K.; Adu-Danso, E.; Abbey, E.; Dovie, B.D. Choice of household adaptation strategies to flood risk management in Accra, Ghana. City Environ. Interact. 2019, 3, 100023. [CrossRef]

32. Zhou, L.; Wu, X.; Ji, Z.; Gao, G. Characteristic analysis of rainstorm-induced catastrophe and the countermeasures of flood hazard mitigation about Shenzhen city. Geomat. Nat. Hazards Risk 2017, 8, 1886-1897. [CrossRef]

33. Ding, N.; Yu, F.; Liu, J.; Wang, T.; Hua, P.; Gao, Y. Variation trends of precipitation in Shenzhen from 1961 to 2011. J. Water Resour. Water Eng. 2017, 28, 61-64.

34. Chen, Z.; Wang, H.; Zhang, X. Research on a new-generation of rainstorm intensity formula for Shenzhen City. J. Nat. Disasters 2007, 16, 29-34.

35. Cui, P.; Guan, Y.; Zhu, Y. Flood Loss Prediction of Coastal City Based on GM-ANN. In Proceedings of the International Conference on Grey Systems and Intelligent Services (GSIS), Stockholm, Sweden, 8-11 August 2017; pp. 187-190. 
36. Tanner, A.; Árvai, J. Perceptions of Risk and Vulnerability Following Exposure to a Major Natural Disaster: The Calgary Flood of 2013. Risk Anal. 2018, 38, 548-561. [CrossRef] [PubMed]

37. Lindell, M.K.; Arlikatti, S.; Huang, S. Immediate behavioral response to the 17 June 2013 flash floods in Uttarakhand, North India. Int. J. Disaster Risk Reduct. 2019, 34, 129-146. [CrossRef]

38. Meyer, M.A.; Mitchell, B.; Purdum, J.C.; Breen, K.; Iles, R.L. Previous hurricane evacuation decisions and future evacuation intentions among residents of southeast Louisiana. Int. J. Disaster Risk Reduct. 2018, 31, 1231-1244. [CrossRef]

39. Lemée, C.; Fleury-Bahi, G.; Navarro, O. Impact of Place Identity, Self-Efficacy and Anxiety State on the Relationship Between Coastal Flooding Risk Perception and the Willingness to Cope. Front. Psychol. 2019, 10, 499. [CrossRef]

40. Babcicky, P.; Seebauer, S. Unpacking Protection Motivation Theory: Evidence for a separate protective and non-protective route in private flood mitigation behavior. J. Risk Res. 2019, 22, 1503-1521. [CrossRef]

41. Bubeck, P.; Botzen, W.J.W.; Laudan, J.; Aerts, J.C.J.H.; Thieken, A.H. Insights into Flood-Coping Appraisals of Protection Motivation Theory: Empirical Evidence from Germany and France. Risk Anal. 2018, 38, 1239-1257. [CrossRef]

42. Zaalberg, R.; Midden, C.J.H. Living Behind Dikes: Mimicking Flooding Experiences. Risk Anal. 2013, 33, 866-876. [CrossRef] [PubMed]

43. Botzen, W.J.W.; Kunreuther, H.; Czajkowski, J.; de Moel, H. Adoption of Individual Flood Damage Mitigation Measures in New York City: An Extension of Protection Motivation Theory. Risk Anal. 2019, 39, 2143-2159. [CrossRef] [PubMed]

44. Peng, L.; Tan, J.; Lin, L.; Xu, D. Understanding sustainable disaster mitigation of stakeholder engagement: Risk perception, trust in public institutions, and disaster insurance. Sustain. Dev. 2019, 27, 885-897. [CrossRef]

45. Fox-Rogers, L.; Devitt, C.; O'Neill, E.; Brereton, F.; Clinch, J.P. Is there really "nothing you can do"? Pathways to enhanced flood-risk preparedness. J. Hydrol. 2016, 543, 330-343. [CrossRef]

46. Dittrich, R.; Francis, B.; Hatzinger, R.; Katzenbeisser, W. A paired comparison approach for the analysis of sets of Likert-scale responses. Stat. Model. Int. J. 2016, 7, 3-28. [CrossRef]

47. van Valkengoed, A.M.; Steg, L. Meta-analyses of factors motivating climate change adaptation behaviour. Nat. Clim. Chang. 2019, 9, 158-163. [CrossRef]

48. Agbo, A.A. Cronbach's Alpha: Review of Limitations and Associated Recommendations. J. Psychol. Afr. 2010, 20, 233-239. [CrossRef]

49. Arunrat, N.; Wang, C.; Pumijumnong, N.; Sereenonchai, S.; Cai, W. Farmers' intention and decision to adapt to climate change: A case study in the Yom and Nan basins, Phichit province of Thailand. J. Clean. Prod. 2017, 143, 672-685. [CrossRef]

50. Viglione, A.; Di Baldassarre, G.; Brandimarte, L.; Kuil, L.; Carr, G.; Salinas, J.L.; Scolobig, A.; Blöschl, G. Insights from socio-hydrology modelling on dealing with flood risk-Roles of collective memory, risk-taking attitude and trust. J. Hydrol. 2014, 518, 71-82. [CrossRef]

51. Lawrence, J.; Quade, D.; Becker, J. Integrating the effects of flood experience on risk perception with responses to changing climate risk. Nat. Hazards 2014, 74, 1773-1794. [CrossRef]

52. Lee, Y.; Tung, C.; Lin, S. Attitudes to climate change, perceptions of disaster risk, and mitigation and adaptation behavior in Yunlin County, Taiwan. Environ. Sci. Pollut. Res. Int. 2019, 26, 30603-30613. [CrossRef] [PubMed]

53. Huang, J.; Cao, W.; Wang, H.; Wang, Z. Affect Path to Flood Protective Coping Behaviors Using SEM Based on a Survey in Shenzhen, China. Int. J. Environ. Res. Public Health 2020, 17, 940. [CrossRef] [PubMed]

(C) 2020 by the authors. Licensee MDPI, Basel, Switzerland. This article is an open access article distributed under the terms and conditions of the Creative Commons Attribution (CC BY) license (http://creativecommons.org/licenses/by/4.0/). 